\title{
Mining
}

\section{The application of sampling theory in bauxite protocols}

\section{Teoria da amostragem aplicada aos protocolos de bauxita}

\author{
Daniel Armelim Bortoleto \\ Department of Mining and Petroleum Engineering, \\ University of São Paulo, Brazil \\ bortoda@usp.br
}

\section{Ana Carolina Chieregati \\ Doutor Professor \\ Department of Mining and Petroleum Engineering, University of São Paulo, Brazil \\ ana.chieregati@gmail.com}

\section{Antônio Henrique Rietra Pereira \\ Alcoa World Alumina, Juruti Mine, Brazil \\ antonio.h.pereira@alcoa.com.br}

\section{Raiza Cavalcante Oliveira}

Alcoa World Alumina, Juruti Mine, Brazil

raiza.oliveira@alcoa.com.br

\begin{abstract}
The applications of Gy's formula are appropriate for calculating variances of the fundamental sampling error (FSE) at any stage of the sampling protocol and before samples are collected as well. However, the formula can be inaccurate because general factors are used to estimate the ore characteristic. In order to allow the calculation of fundamental sampling error and the minimum representative sample masses without using Gy's factors, there are experiments to calibrate the sampling parameters, name$l y$ : the heterogeneity test (HT); the sampling tree experiment (STE) and the segregation free analysis (SFA). The present work describes the experimental procedure for the three calibration methods using bauxite and shows the correlation between them.
\end{abstract}

Keywords: sampling protocols; fundamental sampling error; bauxite.

\section{Resumo}

A fórmula de Gy é apropriada para calcular a variância do erro fundamental de amostragem (FSE), em qualquer estágio do protocolo de amostragem e, mesmo, antes de a amostra ser coletada. Entretanto a fórmula pode ser inacurada por utilizar fatores aproximados para todos os tipos de minérios. Para calcular a variância do erro fundamental de amostragem e as massas mínimas das amostras sem usar os fatores de Gy, existem experimentos para calibrar os parâmetros de amostragem, a saber: teste de heterogeneidade (HT); experimento da árvore (STE) e análise de segregação livre (SFA). O presente trabalho descreve os procedimentos experimentais para a bauxita, utilizando esses três métodos de calibração, e apresenta a correlação entre eles.

Palavras chave: Protocolos de amostragem, erro fundamental de amostragem, bauxita.

\section{Introduction}

Sampling theory of broken material ores cannot be mentioned without a direct reference to Gy's fundamental contributions (Gy, 1998). According to Minnnitt

(2007) apud François-Bongarçon (1998), the fundamental sampling error (FSE) is the smallest achievable residual average error, because of the physical and chemi-

$$
\mathrm{S}^{2} \mathrm{FSE}=\mathrm{c} \mathrm{fg} 1 \mathrm{dN}^{3}\left(\frac{1}{\mathrm{M}_{\mathrm{S}}}-\frac{1}{\mathrm{M}_{\mathrm{L}}}\right)
$$

factor, $g$ is the granulometric factor, 1 is the liberation factor and $\mathrm{dN}$ is the "top size". Furthermore, the formula allows sample, ML is the mass of the original lot, $\mathrm{c}$ is the mineralogical factor, $\mathrm{f}$ is the shape cal composition as well as the particle size distribution. FSE can be determined by Gy's formula, applicable to all kinds of ore (Equation 1):

the calculation of the minimum sample mass to represent a lot for a maximum variance. The experiments developed to 
estimate the sampling constants $\mathrm{K}$ and alpha of Equation 2 are described as follows, where $\mathrm{K}$ is a specific constant to a given ore type at a given grade, and

$$
\mathrm{S}^{2} \mathrm{FSE}=\mathrm{K} \mathrm{\textrm {d } _ { \mathrm { N } }}{ }^{\alpha}\left(\frac{1}{\mathrm{M}_{\mathrm{S}}}-\frac{1}{\mathrm{M}_{\mathrm{L}}}\right)
$$

\section{Methodology}

\section{Heterogeneity test (HT)}

Initially, a $500 \mathrm{~kg}$ sample representing the typical aluminium ore was selected at the mine, then crushed and screened in four size fractions: "-38.1 mm +25.4 mm"; “-25.4 mm +12.7 mm";

The estimated constant factor of constitutional heterogeneity, EST IHL, was calculated according to Equation

The heterogeneity test allows the experimental calibration of the sam-

\section{Sampling tree experiment (STE)}

The sampling tree experiment proposed by François-Bongarçon (Minnitt (2007) apud François-Bongarçon 1995 and 1998) follows a detailed analysis of the application of Gy's formula to determine the fundamental sampling error. A representative $60 \mathrm{~kg}$ sample was collected at the mine. The primary crushing stage using a jaw crusher reduces the ore nominal size to a uniform $95 \%$ passing 25.4 $\mathrm{mm}$. One quarter of the total lot is split out

\section{Segregation free analysis (SFA)}

Both the heterogeneity test and the sample tree experiment suffer from weaknesses that cast suspicion on the derived values for $\mathrm{K}$ and alpha. Minnitt
“-12.7 mm +6.3 mm”; “- $6.3 \mathrm{~mm}+1.2$ mm”. For each size fraction, 50 groups of at least 50 fragments each, collected one by one at random, were selected. Once samples were weighted and analyzed, the

$$
\mathrm{aQ}_{\mathrm{Q}}=\frac{1}{\mathrm{M}_{\mathrm{Q}}} \sum \mathrm{a}_{\mathrm{q}} \mathrm{M}_{\mathrm{q}}
$$

4 , for each of the four size fractions. These factors generate a regression line calculated using the four resulting

$$
\text { EST IHL }=g \sum \frac{\left(a_{\mathrm{q}}-\mathrm{a}_{\mathrm{Q}}\right)^{2}}{\mathrm{aq}_{\mathrm{Q}}^{2}} \cdot \frac{\mathrm{M}_{\mathrm{q}}^{2}}{\mathrm{M}_{\mathrm{Q}}}
$$

pling constants $\mathrm{K}$ and alpha, which must be calibrated for each particular

and forms the first nominal size fraction. The remainder of the ore is then crushed to $95 \%$ passing in $6.3 \mathrm{~mm}$ and the lot is then split into three equal portions. One of these portions is set aside and constitutes the second nominal size fraction. The remaining two fractions are recombined, crushed to $95 \%$ passing $2.0 \mathrm{~mm}$ and split into two portions of equal mass. One portion is set aside as the third nominal size fraction and the remaining one, crushed to

$$
\ln \left(\mathrm{s}_{\mathrm{FSE}}^{2} \mathrm{M}_{\mathrm{S}}\right)=\alpha \ln \left(\mathrm{d}_{\mathrm{N}}\right)+\ln (\mathrm{K})
$$

et al. (2011) proposed a new test called segregation free analysis (SFA). The nominal (average) fragment size, $\mathrm{dN}$, for a fragment passing between two screens

$$
\mathbf{d}_{\mathbf{N}}=\sqrt[3]{\frac{\mathrm{USS}^{3}+\mathrm{LSS}^{3}}{2}}
$$

+0.84 mm"; “- $0.84 \mathrm{~mm}+0.60 \mathrm{~mm}$ ”; “- $0.60 \mathrm{~mm}+0.5 \mathrm{~mm}$ ”; “- $0.5 \mathrm{~mm}+0.3$ mm”; “- $0.3 \mathrm{~mm}+0.23 \mathrm{~mm}$ ”; “- 0.23 mm +0.15 mm"; "-0.15 mm +0.10 mm"; “- $0.10 \mathrm{~mm}+0.07 \mathrm{~mm}$ "; “- $0.07 \mathrm{~mm}+$ $0.05 \mathrm{~mm}$ ”; “- $0.05 \mathrm{~mm}+0.03 \mathrm{~mm}$ ”. alpha, is the exponent of original Gy's cubic formula mass $\mathrm{Mq}$ and grade aq for each group of fragments, as well as the average masses $\mathrm{Mq}$ and weighted average grades $\mathrm{aQ}$ were calculated according to Equation 3 (Koyama et al., 2010).

points, which allows estimating the parameters $\mathrm{K}$ and alpha of Equation 2 (Pitard, 1993).

ore at a particular grade.
$95 \%$ passing $0.1 \mathrm{~mm}$, composes the fourth nominal size fraction. This procedure generates four portions of more or less equal mass, about $15 \mathrm{~kg}$. Using a riffle splitter, each of these portions is now split into 32 sub-samples per fraction. All samples are weighted and chemically analysed. According to Minnitt et al. (2007), the form of Gy's equation can be changed by taking the logarithms of both sides, transposing to Equation 5.

is given by Equation 6, where USS is the upper screen size and LSS is the lower screen size.

Each size fraction was split using a riffle splitter into a series of 32 samples and sent to the chemical laboratory. The variance of the sample series associated with each fragment size was calculated and plotted to produce a straight line 
which can be used to calculate $K$, alpha and liberation size, $d_{l}$. Provided that the screen sizes are chosen such that the

The granulometric factor $\mathrm{g}$ is replaced here by g', where g' $=g^{\prime}(r)$ is read off the curve of granulometric factor ratio $\mathrm{r}=\mathrm{d}_{\mathrm{MAX}} / \mathrm{d}_{\text {MIN }}$ is reasonably consistent, all points representing different $d_{\text {MAX }}$ values on the calibration curve will

$$
\mathrm{S}^{2} \mathrm{FSE}=\mathrm{c} \mathrm{fg} \mathrm{g}^{\prime} 1 \mathrm{~d}^{3}\left(\frac{1}{\mathrm{M}_{\mathrm{S}}}-\frac{1}{\mathrm{M}_{\mathrm{L}}}\right)
$$

g' vs ratio $r=d_{\text {MAX }} / d_{\text {MIN }}$, for closely screened materials.

The liberation factor is the transi-

$$
\mathrm{l}=\left(\frac{\mathrm{d}_{1}}{\mathrm{~d}_{\mathrm{MAX}}}\right)^{(3-\mathrm{a})}
$$

taking the $\log$ on both sides. The linear regression built using the 14 resulting

$$
\ln \left(\mathrm{S}_{\text {rel }}^{2} \mathrm{M}_{\mathrm{S}}\right)=\alpha \ln \left(\mathrm{d}_{\mathrm{MAX}}\right)+\ln (\mathrm{K})
$$

\section{Results and discussion}

\section{Heterogeneity test (HT)}

EST IHL was calculated using Equation 4. Table 1 shows the results of EST IHL for each fragment size (shown in $\mathrm{cm}$ ). The granulometric

\begin{tabular}{ccccc}
\hline $\mathbf{d}_{\mathrm{N}}$ & 3.32 & 2.09 & 1.05 & 0.5 \\
\hline EST IH & 0.823 & 0.337 & 0.149 & 0.008 \\
\hline
\end{tabular}

Figure 1 shows the correlation between the nominal size and $E S T I H_{L}$. The equation of the power trendline

$\left(y=c^{*} x^{\wedge} b\right)$ built for the four fragment sizes gives the sampling parameters $\mathrm{K}$ ( $c$ of the trendline equation) and alpha represent the formula for the relative variance given by Equation 7 .

tion between the liberated, calculable variance, to the non-liberated one given by Equation 8 .

points gives the sampling parameters $\mathrm{K}$ and alpha.

factor for calibrated material is 0.55 (Gy, 1998).

Table 1

EST IH $\mathrm{L}_{\mathrm{L}}$ results for corresponding nominal size

( $b$ of the trendline equation).

Figure 1

Correlation between $\mathrm{IH}_{\mathrm{L}}$ and the fragment nominal size

respectively.

in Table 2.

Table 2

STE statistical results

ance, and $\mathrm{M}_{\mathrm{s}}$ is the sample average mass. Four fragment sizes were used to build relative variance $\left(\sigma^{2}\right)$ is the product

between average grade and relative vari-

\begin{tabular}{|c|c|c|c|c|c|c|c|}
\hline Serie & $\begin{array}{l}\text { Total } \\
\text { Mass }\end{array}$ & $\begin{array}{l}\text { Average } \\
\text { Grade }\end{array}$ & CV & $\begin{array}{c}\text { Relative } \\
\text { VAR }\end{array}$ & $\begin{array}{l}\text { Stnd. Rel } \\
\text { VAR }\end{array}$ & $\operatorname{Ln}\left(d_{N}\right)$ & $\operatorname{Ln}\left(\sigma^{2} \times M s\right)$ \\
\hline 1 & 477.3 & 48.17 & 0.0254 & 0.0006 & 0.0312 & 0.9322 & 2.7005 \\
\hline 2 & 460.48 & 47.86 & 0.0126 & 0.0002 & 0.0076 & -0.4541 & 1.2503 \\
\hline 3 & 459.96 & 47.62 & 0.0195 & 0.0004 & 0.0181 & -1.6094 & 2.1219 \\
\hline 4 & 407.03 & 48.06 & 0.0067 & 0 & 0.0022 & -4.5469 & -0.1191 \\
\hline
\end{tabular}

statistical treatment as described by Minnitt et al. (2007) and are presented
Where relative variance is $\mathrm{CV}^{2}$

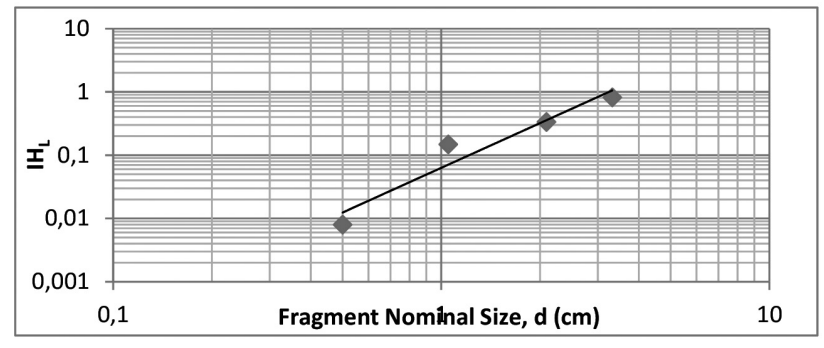

According to Figure 1, the estimates for $\mathrm{K}$ and alpha are 0.0638 and 2.34

\section{Sampling tree experiment (STE)}

The alumina content and the sample masses were submitted to a 
the regression line (Figure 2) according

Figure 2

$K$ and alpha calibration curve for a $47.8 \%$

$\mathrm{Al}_{2} \mathrm{O}_{3}$ ore.

The exponential function of the intercept on the $y$-axis provides an

\section{Segregation free analysis (SFA)}

The alumina content and the sample masses for the 14 size fractions were submitted to a statistical treatment as

Table 3

SFA statistical results

The 14 fragment sizes were used

Figure 3

$K$ and alpha calibration curve for a $50.2 \%$

$\mathrm{Al}_{2} \mathrm{O}_{3}$ ore

According to SFA, the estimates for

to Equation 5.

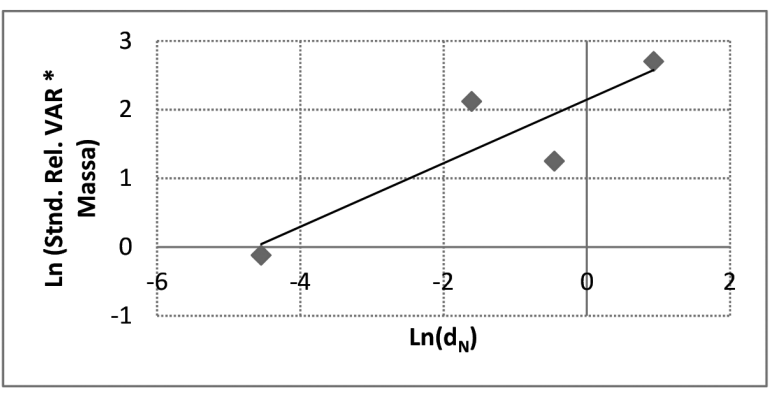

estimate of K. According to the sampling tree experiment, the estimates for $K$ and alpha are 8.54 and 0.46 respectively. described by Minnitt et al. (2011) and are presented in Table 3. The relative variance is $\mathrm{CV}^{2}$ (coefficient of variation), standard relative variance $\left(\sigma^{2}\right)$ is the product between average grade and relative variance and $\mathrm{Ms}$ is the sample average mass.

\begin{tabular}{|c|c|c|c|c|c|c|c|}
\hline Serie & Total Mass & $\begin{array}{c}\text { Average } \\
\text { Grade }\end{array}$ & $C V$ & $\begin{array}{c}\text { Relative } \\
\text { VAR }\end{array}$ & $\begin{array}{l}\text { Stnd. Rel } \\
\text { VAR }\end{array}$ & $\operatorname{Ln}(d N)$ & $\operatorname{Ln}\left(\sigma^{2} \times M_{s}\right)$ \\
\hline 1 & 360.07 & 50.98 & 0.04 & 0.0019 & 0.097 & 0.932 & 3.556 \\
\hline 2 & 168.19 & 51.17 & 0.04 & 0.0013 & 0.064 & 0.239 & 2.381 \\
\hline 3 & 176.61 & 48.77 & 0.02 & 0.0004 & 0.019 & -0.454 & 1.197 \\
\hline 4 & 11 w3.37 & 50.51 & 0.01 & 0.0001 & 0.007 & -1.966 & -0.223 \\
\hline 5 & 59.80 & 47.74 & 0.01 & 0.0001 & 0.005 & -2.465 & -1.215 \\
\hline 6 & 27.58 & 49.51 & 0.01 & 0.0001 & 0.004 & -2.813 & -2.132 \\
\hline 7 & 43.29 & 49.66 & 0.01 & 0.0001 & 0.006 & -2.996 & -1.300 \\
\hline 8 & 26.34 & 50.32 & 0.02 & 0.0003 & 0.017 & -3.507 & -0.803 \\
\hline 9 & 38.11 & 49.78 & 0.01 & 0.0002 & 0.008 & -3.854 & -1.213 \\
\hline 10 & 40.08 & 50.48 & 0.01 & 0.0002 & 0.008 & -4.200 & -1.097 \\
\hline 11 & 46.21 & 53.14 & 0.01 & 0.0001 & 0.003 & -4.547 & -2.010 \\
\hline 12 & 34.32 & 50.83 & 0.01 & 0.0002 & 0.011 & -4.893 & -0.942 \\
\hline 13 & 40.82 & 50.53 & 0.01 & 0.0001 & 0.007 & -5.240 & -1.184 \\
\hline 14 & 39.64 & 50.03 & 0.01 & 0.0000 & 0.002 & -5.573 & -2.686 \\
\hline
\end{tabular}

to build the regression line on Figure 3, according Equation 9.

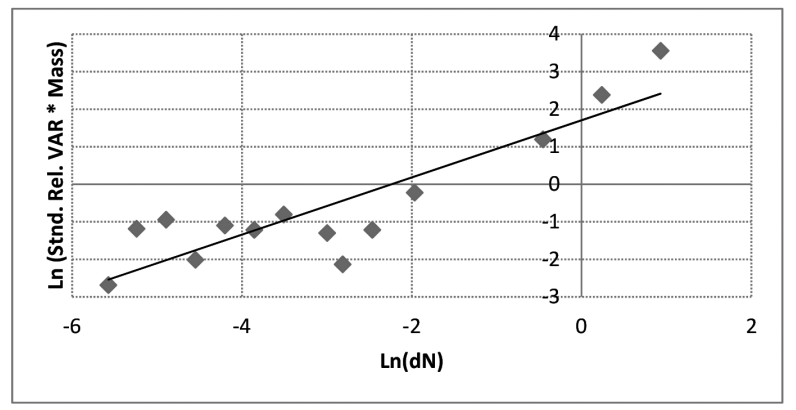

K and alpha are 5.49 and 0.76 respectively.

\section{Comparison between sampling protocols using HT, STE and SFA}

Table 4 shows the values of Gy's factors (Pitard, 1993) for Juruti's bauxite according to Equation 1. 


\begin{tabular}{ccccccccc}
\hline Factor & $\mathrm{c}$ & $\mathrm{f}$ & $\mathrm{g}$ & $\mathrm{di}$ & $\mathrm{Al}_{2} \mathrm{O}_{3}$ & $\lambda \mathrm{M}$ & $\lambda \mathrm{G}$ & $\mathrm{IH}_{\mathrm{L}}$ \\
\hline Values & 3.6 & 0.5 & 0.25 & 0.00036 & $48.1 \%$ & 3.98 & 2.65 & $0.0085 \mathrm{~d}^{2.5}$ \\
\hline
\end{tabular}

Table 5 shows the sampling and sample preparation protocol for Juruti's mine and the relative standard deviation of the fundamental sampling error (last 4 columns, in \%), $\mathrm{s}_{\mathrm{FSE}}$, of each stage using Gy's factors $(\mathrm{Gy}, 1998)$ as well as the

\begin{tabular}{cccccccc}
\hline Step & $\mathbf{M}_{\mathrm{L}}(\mathrm{g})$ & $\mathbf{M S}(\mathrm{g})$ & $\mathrm{d}_{\mathrm{N}}(\mathrm{cm})$ & $\mathbf{s}_{\mathrm{FSE}} \mathrm{GY}$ & $\mathbf{s}_{\mathrm{FSE}} \mathbf{H T}$ & $\mathbf{s}_{\mathrm{FSE}}$ STE & $\mathbf{s}_{\mathrm{FSE}}$ SFA \\
\hline Primary Samping & $1.5 \mathrm{E}+10$ & 15000 & 5 & 0.5628 & 1.3461 & 3.4618 & 3.5328 \\
Crushing & 15000 & 15000 & 2.54 & 0.0000 & 0.0000 & 0.0000 & 0.0000 \\
Primary Quartering & 15000 & 2500 & 2.54 & 0.5397 & 1.3632 & 6.6183 & 6.1023 \\
Grinding & 2500 & 2500 & 0.2 & 0.0000 & 0.0000 & 0.0000 & 0.0000 \\
Secondary Quartery & 2500 & 200 & 0.2 & 0.0836 & 0.2592 & 13.6578 & 8.6044 \\
Pulverization & 200 & 200 & 0.015 & 0 & 0 & 0 & 0 \\
\hline TOTAL & & & $\mathbf{0 . 7 8 4} \%$ & $\mathbf{1 . 9 3 3} \%$ & $\mathbf{1 5 . 5 6 7 \%}$ & $\mathbf{1 1 . 1 2 5} \%$ \\
\hline
\end{tabular}

Considering Equation 2, a maximum relative standard deviation of the fundamental error of $3 \%$ and a high value

\begin{tabular}{|c|c|c|c|c|}
\hline Parameter & GY & HT & STE & SFA \\
\hline $\mathrm{d}_{\mathrm{MAX}}(\mathrm{cm})$ & 5 & 5 & 5 & 5 \\
\hline $\mathrm{M}_{\mathrm{S}}(\mathrm{g})$ & 530 & 3.063 & 19.895 & 20.728 \\
\hline $\mathrm{d}_{\text {MAX }}(\mathrm{cm})$ & 1 & 1 & 1 & 1 \\
\hline $\mathrm{M}_{\mathrm{S}}(\mathrm{g})$ & 9 & 71 & 9.486 & 6.099 \\
\hline
\end{tabular}

Table 4

Factors used in Gy's relative variance equation

results of HT, STE, SFA.

Table 5

Sampling protocol comparing the three heterogeneity experiments

can be calculated. The last line of table 6 shows the same calculations for a $d_{\text {MAX }}$ of $1 \mathrm{~cm}$.

Table 6

Minimum sample masses (Ms) for the primary sample at the mine

\section{Conclusions}

This paper presented a comparison of different methods to estimate the variance of the fundamental sampling error, minimum sample masses and the sampling parameters by different methods. An appropriate sampling protocol for any type of ore requires experimental test work in order to determine the deposit's heterogeneity. The heterogeneity test (HT) has been used for several decades and has proved to be an excellent method to calculate the minimum representative sample masses and to optimize sampling protocols during the beginning of mining projects and during operation as well. However, the new proposed tests show significant differences which should be taken into account. The comparison between the results of STE and SFA shows the relationship between the fundamental sampling error and the grouping and segregation error. SFA was developed aiming to eliminate the residual grouping and segregation variance which biases the calibration curve and should present smaller variances than STE. However, for higher diameters, SFA presents higher values of s2SFE, suggesting that the fundamental sampling error makes the most important role for coarser particles. Based on the results, the company decided to adopt the segregation free analysis for defining its sampling protocols due to two major reasons: (1) the SFA proved to reduce the grouping and segregation error and (2) the SFA presented higher minimum sample masses than the heterogeneity test, making this method safer than the HT with respect to the representativeness of samples. The results showed that optimizing sampling protocols is not a simple task and more than one experimental test should be performed to confirm what the minimum sample masses should be. This paper is a study for bauxite and may be not applicable to other types of ore. The authors highly recommend other companies to compare the different approaches and define the most suitable for their operations.

\section{Acknowledgments}

The authors acknowledge Alcoa World Alumina and University of São Paulo for their support in conducting the research and producing this paper.

\section{References}

GY, P.M. Sampling for analytical purposes. West Sussex, England: JohnWiley \& Sons, 1998. (Translated by A.G. Royle).

PITARD, F.F. Pierre Gy's sampling theory and sampling practice. (2. ed.). CRC Press, Boca Raton, 1993.

KOYAMA, I.K., CHIEREGATI, A.C., ESTON, S.M. Teste de heterogeneidade como método de otimização de protocolos de amostragem. Brasil Mineral, v. 27, 
p. 63-68, 2010.

MINNITT, R.C.A., RICE, P.M., SPANGENBERG C.. Part 2: Experimental calibration of sampling parameters $\mathrm{K}$ and alpha for Gy's formula by the sampling tree method. The Journal of The Southern African Institute of Mining and Metallurgy, p. 513-518, 2007.

MINNITT, R.C.A., FRANÇOIS-BONGARÇON, D., PITARD, F.F. 2011. Segregation Free Analysis for calibrationg the constants $\mathrm{K}$ and $\alpha$ for use in Gy's formula. In: WORLD CONFERENCE ON SAMPLING AND BLENDING, 5. Gecamin, Santiago, p.133-150.

MINNITT, R.C.A. APUD FRANÇOIS-BONGARÇON, D. Gy's Formula: Conclusions of a new phase of research. Proceedings Australian Association of Geoscientists. v.22, 1998.

sing, v. 29, n. 3-4, p. 149-174, 1990.

Received: 08 September 2013 - Accepted: 23 March 2013. 